\title{
Disruption in Manufacturing Industry Future of Global Workforce
}

\author{
Dr. Dayo Bambe
}

\begin{abstract}
The aim of this research was to evaluate the future of the global workforce aligned with the disruptive technologies in the manufacturing industry. The impacts of $5 \mathrm{G}$, robotics, artificial intelligence, and machine learning were focused on current research. The purpose was to identify the possible safety net, which could be used by the governments and regulatory authorities to deal with the negative effects of technologies on the workers' displacement in the next 5 to 10 years. Through the implementation of the inductive research methodology based on structured survey questionnaire administered with the sample of 100 employees working in the manufacturing sector, effects of disruptive technologies on the employment situation, production activity and overall organisation performance were addressed. Findings of the investigation have confirmed that new technologies have positive impacts on the production activity and overall organisational performance. New technologies are contributing vitally to increasing the production output, production quality, improving the cost of delays, increasing efficient waste management, reliable and consistent growth and enhanced profitability for the manufacturing companies. In contrary, these technologies are also having negative effects on the employment situation such as reduced recruitment, training, compensation, and increased unrest. Lastly, the set of recommendations directing towards introducing governmental regulations and policies for mandatory training, balanced compensation and increased hiring, are expected to have a significant positive contribution for tackling the issue of displacements.
\end{abstract}

\section{Background}

\section{CHAPTER ONE: INTRODUCTION}

Technologies and new scientific innovations are taking hold over the traditional modes of working and interaction among the different stakeholders to diversify business sectors and industries. These innovations have ultimately lead to automation impact on the global workforce, creating a severe extent of anxiety and curiosity among the individuals. Currently, $5 \mathrm{G}$, robotics, artificial intelligence, and machine learning are gaining significance due to their contribution in changing the dynamics of business working in terms of cost, quality, schedule, and approach to implement business strategies (Shi, 2011). All these emerging technologies are advancing at a rapid pace due to their ability to help the business organisation developing as well as maintaining their competitive position within the market. $5 \mathrm{G}$ is the next generation of mobile communication, playing a vital role in transmitting industries towards the adoption of cloud technologies. Likewise, the increased development of intelligent machines designed and trained to work and behave like humans, with an aim to enhance productivity and profitability (Poole \& Mackworth, 2017).

Despite innumerable and invisible benefits of these technologies for the businesses, on the other side, these technologies are adding to the challenges and concerns of the global workforce. One of the biggest concerns is related to the risks of job loss or takeover by the robots and machines. According to the Forbes, "Technology has already taken over $90 \%$ of the jobs humans used to do" (Quora, 2018). In a similar context, considerable terrifying instances 
currently are dispersed around the railroad industry, NASA, Agriculture and Farming. In the contemporary environment, with the emerging inventions and proliferation of technologies in the agriculture industry, only a small percentage of farmers are needed to grow plenty of food for the constantly increasing global population. Additionally, when the NASA for the calculation of flight trajectories earlier employed a large group of people, the present situation is completely opposite due to the reduced size of the human workforce and the increased percentage of self-computing devices (Quora, 2018).

Secondly, the other biggest technology-led change is associated with the continuous growth of the non-employer business, termed as sharing economy businesses frequently. These businesses such as Uber, Airbnb, and Amazon have allowed the significant rise in the independent workers who prefer to work on unpredictable schedules and within flexible working hours. However, such online technology influences are considerably reducing the traditional employees' workplaces, making a distant gap for the unskilled and non-educated labour force in the employment industry (Rosen, 2015).

Thirdly, some of the industry sectors are at high risk due to their nature as readily automatable sector and enhanced technical potential. According to a research report published by McKinsey \& Company, $100 \%$ of the activities in the manufacturing sector, $73 \%$ of the activities in food service and accommodation, $53 \%$ of the activities in retailing possess the technical feasibility of being automated (Chui, et al., 2016).

The disruptions caused by the technologies in the global business industries have started displacing workforce (e.g. workforce restructuring in global multinational) (Rigby, 2016). Furthermore, according to the survey conducted by the Economics Times for assessing the effects of emerging technologies on job losses and layoffs. The findings of the survey revealed that $81 \%$ of the respondents highlighted the need to retrain or reskill themselves in order to capture better job prospects. Consequently, e-learning companies such as Skillsoft are gaining immense importance among the workers, in order to acquire specialised competencies associated with IT analytics and product management (ET Online, 2017).

Despite these terrifying instances, in contrary, the policy makers and governments in their public policy do not address such impacts on employment and provide reasonable solutions (Karsten \& West, 2015). Likewise, the international community is also up to a greater extent, non-responsive to the resulting displacement and disruption of the workforce in the global industries. Furthermore, there has been disagreement among the experts on the size of the automation impact on the global workforce, as according to them, these new technologies are potentially able to create more jobs and employment opportunities for the workforce in the future (Manyika, et al., 2013).

In a paper published by OECD, (2018), far-reaching impacts of the transformative technologies were reported, requiring structural changes in the business models leading and to head towards the formation of digital intensive businesses. In past relatively, for the scientific technologies i.e. 5G, AI, ML, robots, which were non-accessible due to the high cost, are becoming cheaper for the business organisations (OECD, 2018). Ranging from the manufacturing to service sector organisation from small and medium enterprises two large ones, are the widespread application of these technologies has been evidenced in the recent decade. Therefore, it is highly necessary for the potential stakeholders in public policy and the international community to measure the large impacts of the technologies on the global workforce. 


\section{Research Issue}

Similarly, manufacturing industry is considered as one of the biggest executed the and implementer of the artificial intelligence and machine learning in order to drive smart manufacturing process and smart factories. The industry has already started showing massive disruptions integrating exciting ways of manufacturing using these technologies. Large international players in the manufacturing industry, indifferent subsectors such as General Electric's, Siemens, Intel, Microsoft, Nvidia and others are making significant research and development as well as potential investments in embracing these transformative technologies in reducing their labour cost, decreasing product effects, shortening unplanned downtimes and further enhancing the production speed (Walker, 2018). Consequently, the industry is requiring fewer workers for the accomplishment of the task, which was completed traditionally by a large group of workers simultaneously. Digitalisation has reshaped the production cycle and therefore it is highly necessary to measure the effects on the workforce for the future. Automation has resulted in disastrous job losses within the manufacturing organisations across the globe. Reports are introduced for the performance of accumulating as well as movement dependent actions carried out on the manufacturing floor (McKinsey Global Institute, 2017). Furthermore, these technologies are also playing their significant role in enhancing communication and planning performances for the manufacturing activities, through real-time connectivity between the factories and administrative departments. The roles of manual data managers, planners, and communicators have been reduced by new communication technologies with a larger set of capabilities. Jobs occupied by robots indicate the need for a possible safety net developed by governments and policymakers as well as the international community to protect the labour sectors from the currently free-flowing effects of the disruptive technologies. The current research tends to draw together strands of such impacts on the labour of manufacturing sector, from the perspectives of the next 5 to 10 years.

\section{Aims and Objectives}

The key aim of the research is to evaluate the future of the global workforce aligned with the disruption in the manufacturing industry. The impacts of $5 \mathrm{G}$, robotics, artificial intelligence, and machine learning are focused on current research. For the successful accomplishment of the stated research team, a comprehensive set of research objectives developed are given below.

- To investigate the current and possible future impacts (over 5 to 10) of disruptive technologies on the global workforce displacement in the manufacturing sector

- To evaluate the current policy measures available for the protection of the global workforce

- To suggest a possible safety net for governments and policymakers as well as the international community for balancing technology disruption impacts for workforce

\section{Research Significance}

The focus of current investigations on the quantitative survey data gathered from the reliable resources and international databases along with the qualitative analysis of the current and possible future effects of $5 \mathrm{G}, \mathrm{AI}, \mathrm{ML}$, and robotics, the current investigation tends to show vital effects. Both theoretical and practical sides of the under investigation issues would contribute vitally in making a vital function towards the existing literature. Furthermore, suggested possible safety net is expected to highlight the main changes needed in the public policy for the protection of the workforce right in the ever-changing technological era.

\section{Research Limitations}

The scope of the current investigation is limited to the investigation of workforce displacement caused by the visible as well as the potential impacts of the discussed new emerging and disruptive technologies. The focused areas of the workforce would be job protection, skills 
maintenance, and wages and compensation. The research tends to include both the qualitative and quantitative information about the impacts of new technologies on the need for workers to modify their current skill sets and performances in order to prevent themselves from displacement within the manufacturing sector.

\section{Research Layout}

The remaining part of the dissertation is divided into the following subsections.

Chapter 2: Literature Review presents a comprehensive and critical review of the academic literature focusing on the theory is associated with disruptive technologies such as artificial intelligence, machine learning, robotics, 5G. Furthermore, the empirical investigations from the global manufacturing companies are discussed to show the potential physical effects of these technologies on the workforce currently.

Chapter 3: Research Methodology endeavours to justify the set of research approach, data collection methods and data analysis methods, selected for the current investigations. The chapter would highlight the need to integrate qualitative and quantitative methods for treating towards an effective conclusion.

Chapter 4: Results and Findings present statistical survey data results gathered from the employers as well as employees of the global manufacturing sector. The main objective behind the survey is to identify the potentials of destructive technologies affecting the workforce of the manufacturing sector over 5 to 10 years.

Chapter 5: Discussion would integrate and cross-relate the findings of the literature with the survey, in order to identify the areas needed for protection and improvements, from the perspective of policy-making.

Chapter 6: Conclusions, Recommendations, And Limitations would present a summary of the key insights and the resulting suggestions in the form of possible safety net required by the policymakers in the international community for protecting the workforce in the manufacturing sector.

\section{Introduction}

\section{CHAPTER TWO: LITERATURE REVIEW}

The chapter presents a critical review of the existing theories and literature, indicating the impacts of disruptive technologies on the global workforce in the manufacturing industry. By focusing on the current impacts of these technologies in the chosen area of the workforce, the chapter would develop a theoretical framework for subsequent survey research.

\section{Disruptive Technologies: Theories and Concepts}

Academic researchers, as well as practitioners, have described disruptive technology as the one, which is potentially able to displace a long-lasting established technology. According to Armstrong, (2017), a disruptive technology can shake up the entire industry, while contributing to the development of the new industry standards. Researchers further substantiated such technologies as the outcome of innovation to drive the development of new markets and value networks for the businesses in different industries. Manyika, et al., (2013) have substantiated further the contribution of the disruptive technologies in reshaping life and work across the globe. The emergence of the mobile internet and movable technologies and the ongoing advancements in their standards and applications have stressed the two key features in defining the disruptive technologies. These features as stated by Ekekwe, (2012) define these technologies like the ones, which have the ability to reduce the resource dependency of 
the firms, up to a greater extent by utilising their resources with the implementation of the new technological approach. Besides, the second feature highlights such technologies as the threatening factors for the existing firms, possibly losing their market dominance in staying unresponsive.

\section{G - Wireless Communication}

The review of the recent literature and secondary data sources have further indicated the rising influence of $5 \mathrm{G}$ wireless communication technologies at the international workplace (Marchetti, 2014). According to them, the new technology has offered a forward-looking approach and novel ways for business performances in different industries and sectors (Osseiran, et al., 2016; Yang Yang, et al., 2017). Sandle, (2018) has emphasised the power of 5G wireless connection technology in affecting the manufacturing sector considerably. The employment of $5 \mathrm{G}$ within the manufacturing sector has allowed improved communication among the different devices and machines through sensors, actuators, and processing units. According to the projected efficiency measured by the local authorities for the 5G wireless communication includes highly efficient and fast cycle times of $0.1 \mathrm{~ms}$, representing a hundredfold improvement on existing wired technologies. In discussing the effectiveness of the $5 \mathrm{G}$ communication for the manufacturing industry, specifically automobile manufacturing, Latif, et al., (2017) have highlighted that the technology has been assisting the manufacturers in saving their costs associated with the product defects and fixtures. By offering constant monitoring and improvement in the production line performance, factories of the organisations are able to deal with the core product issues in time.

Marchetti, (2014) has further added that the next generation of wireless communication system requires the manufacturing organisations to modify the existing drivers and requirements in order to stay attractive to the communicative technologies offering dynamic interaction over the extreme densified networks, including local and international level players in the networks. Similarly, 5G communication has offered human-centric interaction by providing efficiencies and on-demand flow of required data cable of providing enough information along with entertainment to the users. The wireless communication modes further have of dealing with the hectic an inconvenience associated with the wire-based communication systems. The user-friendliness and result-oriented management of data information further allow organisations to perform their daily operational activities and reduce time within the real-time environment. However, the businesses need to understand the diversified requirements associated with the implementation of this wireless communication systems. According to Xiang, et al., (2016) 5G wireless communication requires businesses to have strong latency and reliability requirements, a broad range of data rates, network scalability, and flexibility issues. Similarly, Xiang, et al., (2016) has also criticised the darker side of the implementation of $5 \mathrm{G}$ technology by indicating that despite such enhanced communication can offer bright future to the businesses but would ultimately have significant adverse impacts on the human as it would eliminate the need for human-based information system within the organisations to tackle the exchange of data information among the individuals, departments and between different branches of the organisation as well as across the stakeholders group (Xiang, et al., 2016).

\section{Artificial Intelligence}

Another technology contributing vitally in the human replacement within the global industry is artificial intelligence, which is a field of computer science stressing on the development of intelligent machines having the potentials of functioning and responding like humans (Benyoucef \& Grabot, 2010). The core aspects of artificial intelligence are highlighted in the literature include a speech recognition, learning, planning, and problem-solving. Academic 
researchers (Tarantola, 2017; Daugherty \& Wilson, 2018) have also provided with significant examples of how the smarter automation brought by artificial intelligence to the factory floor of the manufacturing organisations can adversely affect the human workforce at the operational level. In contrary, artificial intelligence offers a great opportunity to humans with advanced skills for the workforce, teaming humans with the robotic AI for remaking modern manufacturing. 3D printing technology provides a great example in this context (Tarantola, 2017). In conjunction, Daugherty \& Wilson, (2018) have highlighted the integration of artificial intelligence in the manufacturing sector has offered a variety of prospects to the organisations including expansion of the kinds of materials for boosting production levels, increased production capability, cost-effectiveness. The researcher has however stressed the need to have effective and appropriate supply chain and regulatory reforms for assisting the manufacturing organisations to tackle the benefits of artificial intelligence effectively.

According to Rendall, (2016), millions of jobs are disappearing from the market due to the enhanced productivity growth originating from the replacement of the human workforce with machines. Global manufacturing organisations justify the replacement and layoffs by indicating the attributes of the artificial machines. They consider these machines are safe, reliable, and more ethical relative to enter the human force comprised of diversifying domestic and foreign labourers. Rendall, (2016) did stress on the core purpose of the organisations in adopting the machine learning and artificial intelligence by emphasising that these are realised as a game changer in the industry, for dealing with cost reduction and the making of returns on investment (ROI) in less than 12 months.

\section{Robotics}

Robotics is also one of the significant technologies, which has also placed significant impacts on the role of humans and business organisations. Robotic is contributing vitally in order to consider Toyota's manufacturing philosophy. Jeffer, (2017) has considered that machines are appropriate for the repetitive things only but these can contribute to the improvement of efficiency as can be done by humans. In a similar context, the Toyota Company has carried out an internal investigation making a comparison of the time taken by individual people and machines for the completion of the task. The findings revealed that human force has won the investigation. The company has added that robotics cannot outperform the system as humans are behind their functioning to assist them in lean production, continuous improvement, assembly lines, and production flows.

Spiegel, (2018) has further added that advances in technologies such as robots have helped the business organisations in dealing with the full employment potentials in some economies too as due to a shortage of working population, business manufacturers are recommended to pursue automation. This would assist in dealing with the high labour costs arising out due to the increased power of the workforce in the industry.

"The economy is generally considered to be are nearing full employment, with the stock market lately showing volatility over the possibility of rising inflation due to a tight employment market and the resulting higher wages. One solution for manufacturers and warehouse managers in the face of rising labour costs is to increase automation. At the Anaheim, Calif., show, panellists agreed the robotics is a natural solution to that issue" (Spiegel, 2018, p. 1).

Subsequent to the review of the different technologies affecting human place within the organization, the next section discusses the current applications of disruptive technologies in the global manufacturing industry. By identifying how the different organizations are 
responding to the automation and technology adoption, the evidence would help in identifying how the novel disruptive technologies are contributing to the human replacement of the manufacturing organizations.

\section{Current Applications of Disruptive Technologies in Global Manufacturing Industry}

According to European Union, (2017), the analysis of the current applications of disruptive technologies in the global manufacturing industry, it can be depicted that policy decisions contribute vitally in influencing the workforce and their working with technology as well as detached with technology. European Union, (2017) has reported further that a range of disruptive technologies is enabling radical changes in different economic sectors and enabling new modes of work, production, and consumption of societal transformations. However, the implementation of these technologies in the manufacturing sector requires the current state of integration to be focused around the new technological affordance. Policy-makers can play a vital role in helping the organisations balancing the use of different kinds of technologies (European Union, 2017).

Mellor, et al., (2014) through a qualitative case study analysis and by constructing in testing innovative structural model of implementation factors, identified one of the significant technological trends prevailing in the global manufacturing sector i.e. additive manufacturing. Business researchers have defined AM as you manufacturing method based on 3D technology used to develop the prototypes for the manufacturing industry. AM offers highly versatile and new design freedom to the manufacturers, ultimately promoting them to switch towards the innovative technologies from the fabricated prototypes. This has ultimately reduced the demand for prototype workers due to the removal of tooling requirements and the introduction of computerised modelling. Besides defining the potentials of this disruptive technology, researchers have also suggested the need to have a comprehensive implementation framework to assess the AM project managers to stay responsive to the new business opportunity and produce high-value products.

Academic researchers (Shin, 2017; Durakbasa \& Gencyilmaz, 2018) have offered great instances for the adoption of diversified technologies affecting the changing modes of operations within the manufacturing industry. Different manufacturing sectors' organisations in different countries are up to a certain extent making employment of new technologies in different manufacturing activities (Wang, et al., 2017; Wang \& Wang, 2017; Thames \& Schaefer, 2017).

Wang, et al., (2017) have highlighted the increasing use of machining and robotics applications in the manufacturing environment. Researchers have proposed the framework need to adopt a flexible architecture based on integrated methodologies for cloud manufacturing system, as a new disruptive trend. Other academic researchers have also confirmed the visible impacts of cloud computing technologies for integrating different physical manufacturing facility presented at different places (Thames \& Schaefer, 2017; Grandinetti, 2013). Grandinetti, (2013) added to the rising significance of the Internet of things and computing technologies in order to obey the traditional manufacturing frameworks. The emerging technologies are capable of aligning the functioning of processes faster.

Another significant implementation of disruptive technology was investigated by the Wang, et al., (2016) in the context of the smart factory for industry 4.0. Findings showed that emerging technologies within the manufacturing sector has given rise to the development of smart factory with flexible features. According to them, a smart factory through its self-organized multi-agent system has been offering the global manufacturers are coordinated cloud 
environment. The integration of the components such as "industrial network, cloud and supervisory control terminals with smart shop floor objects (including machines, conveyors and products)", the smart factory has reduced the burden on the manufacturers. Such an application of the smart factory supports autonomous decision-making, ultimately reducing the need of the human workforce. According to researchers, this disruptive innovation is also aligned with the needs of the contemporary environment associated with big data-based feedback and coordination.

In a similar context, Cheng, et al., (2018) have investigated the emerging application of realtime monitoring and smart communication technology based on 3G, 4G, and 5G communication networks with the massive amount of data generated in the manufacturing process. Researchers further acknowledge the positive impact of these technologies in raising the application of smart manufacturing based on cyber-physical manufacturing system as the dominant development ran across the globe. The further explain the potentials of $5 \mathrm{G}$ in encouraging the implementation of the Internet of things and CPMS for dealing with the advanced manufacturing scenarios.

Kolberg \& Zühlke, (2015) have also discussed one of the significant trend associated with lean automation, aimed towards integration of the existing lean production approaches with the automation technologies in order to reap the benefits of industry 4.0. The trend appears to be supportive in reducing the complexities of the automation technology within the manufacturing sector by connecting it with the traditional approach. Such integration has been helping the manufacturers in avoiding non-value creating process steps from the manufacturing procedure, resulting in the cost-effective and time managed productions. The review of the different applications and friends of disruptive technologies in the global manufacturing sector have informed about the potentials of the technology in taking over all the human-based activities from designing and planning to prototype development and the real-time production. Consequently, besides the future technological potentials over 5 to 10 years, this research is also directed to identify the impacts of current technologies on the workforce of the manufacturing sector. Hence, after gaining a form of the rising disruptive technologies application and trends worldwide, the next section discusses the impact of these technologies are based on the manufacturing workforce.

\section{Empirical Investigations on Current Technologies impacts on Manufacturing Workforce}

A range of past to recent academic studies has confirmed the impacts of new technologies on the labour market and workforce within the global manufacturing industry.

In their analytical study using a dynamic cost function for addressing the impacts of technological, Paul \& Siegel, (2001) have found the larger technological impacts in the form of changes in the labour composition. The indirect effects of technologies were further assessed on the shifts in employment while taking account of the direct impacts on promoting computerisation ultimately worsening the skill-biased technological transformation.

On the other side, Abri \& Mahmoudzadeh, (2015) in the empirical investigations have confirmed the impact of information technologies on the productivity and efficiency of manufacturing industries in Tehran. Based on the penal data findings collected from the 23 Iranian manufacturing industries between the periods of 2002-2006. The findings revealed positive and statistically significant effects of the information technologies on the productivity of manufacturing industries, mainly, which are high IT-intensive. 
The critical review of academic findings has informed about both the positive and negative impacts of information technology on the employment within the manufacturing industry. In conjunction with the positive impacts, Mehta, (2016) has investigated the technological impacts of unemployment within the Indian manufacturing sector. The effects were identified on the employment growth within the different technological intensive industries such as pharmaceuticals, transportation, various metals, and textiles. The results of the comparative analysis for the period 2000 - 2001 to 2013 - 2014 further recommended that need to have a strong and supportive system of innovation for enhancing sustainable employment growth within the manufacturing sector. The critical point highlighted the research was associated with the use of the comprehensive system to support radical innovation in order to deal with the loss of additional employment.

Besides academic studies, research reports have also discussed the effects of technology on job loss and reduction of employment in the global manufacturing sector. In a similar context, Shrek, (2010) has discussed the attempts made by the members of Congress for saving US manufacturing jobs by placing restrictions on the International trade. According to the researcher, accelerating automation trade with US manufacturing is ultimately leading to the loss of employment in the sector through the removal of numerous manual repetition activities and jobs. Shrek, (2010) further believed that the dominant role of technology in driving down the manufacturing employment is much higher relative to the effects of the increased offshoring of the manufacturing operations. Similarly, findings from Autor, et al., (2015) study are also in an argument with the local labour market situation resulting from the increased automation exposure rather than Chines import exposures. These findings have rejected the opinions raised among the US authorities for considering susceptibility of the manufacturing sector to the outsourced markets in terms of labour reduction. The investigators in this research have suggested the rise of occupational polarisation within the manufacturing sector due to intensive automation.

West, (2016) in his research report has acknowledged the potentials of machines in performing creative actions and complex functions. According to him, a number of industrial reports around the world having 1.9 million in 2017 compared to 1.2 million in 2013. The research showed a rapid rise in the use of technologies in the global manufacturing industry such as robots, computerised algorithms, artificial intelligence, augmented reality, medical sensors, 3D printing, and autonomous vehicles. Discussing the substantial effects of information technology and automation on the workforce, West, (2016) has presented the example of Google, where with only 55,000 employees; the company is able to make worth of three \$370 billion. Furthermore, according to the projected statistics in this research, manufacturing sector is estimated to lose a high proportion of jobs within the distant future as according to the expectations of BLS, between 2012 and 2022, US manufacturing sector is expected to cut down 550,000 jobs.

Benedikt Frey \& A.Osborne, (2017) distinctly emphasised the need to understand the relationship between the probability of the occupations of computerisation, increase, or decrease wages and educational attainment. According to them, the effect of computerisation can only be assessed in an economy after analysing its effect on the skill development needs of the existing workers and the level of compensation received after computerisation. Improved scale and wages are ultimately strong contributors to the positive impacts of computerisation and technology on the employment growth. However, in the absence of these two aspects, the negative effects of technological change are evident in the manufacturing occupations. Arntz, et al., (2016) in their earlier study have proposed an occupation-based approach for understanding the risk of computerisation for employment opportunities. Using a similar 
approach, Arntz, et al., (2016) have investigated the US and European countries substantial loss of jobs, assuming the whole occupations rather than single job tasks as automated through technologies. Based on the outcomes of the 21 OECD countries assessed using the task-based approach as well as occupation-based approach, the results revealed that $9 \%$ of the jobs are automatable in these OECD countries. Such a lower percentage of the automatable jobs indicate the automation digitalisation oriented jobless future can be prevented using significant policy frameworks for defining workplace organisations, and the level of investment needed to train the workers according to the emerging technological specifications.

\section{Conclusion}

Thus, the findings of the review of academic literature can be summarised to identify the different emerging technologies currently affecting the manufacturing sector and its workforce, both positively and negatively. The range of literature analysed in the chapter informs about the growing significance and use of the variety of disruptive technologies such as 5G wireless communication, artificial intelligence, robotics, cloud computing and machine learning approaches. A mutual consensus was identified among the academic researchers showing the rising adoption of new technology in the manufacturing sector due to their potential role as a game changer. Additionally, a large percentage of researchers has agreed on the adverse impacts of such technologies on employment growth and job opportunities. They have argued on the effects of lack of policy and regulatory procedure in controlling this disruptive technology-based change in the manufacturing sector on the workforce. Consequently, there has been a significant decline in the manufacturing workforce in the contemporary era both in the developing as well as the developed countries of the world including OECD. Mainly the chapter was an attempt to answer the first research question about current and possible future impacts of disruptive technologies on the global workforce displacement. These literature findings can be used to carry out a primary survey from the employers of the manufacturing sector to identify the current policy measures and possible safety nets for government and policymakers in the international community in order to maintain the balance to the relationship between the disruptive technologies and global workforce. The next chapter of the study presents research methodology, for the data collection and analysis from the primary respondents.

\section{Introduction}

\section{CHAPTER THREE: RESEARCH METHODOLOGY}

The chapter presents the research methodology chosen for searching the answer to the research question i.e. the impacts of disruptive technologies on the future global workforce in the manufacturing industry. For devising a comprehensive research methodology, Saunders, et al., (2003) research onion was employed. The six-layered research onion has supported vitally in justifying the choice of research philosophy, approaches, strategies, time horizons, data collection, and data analysis methods.

\section{Research Philosophy}

The first layer of research onion identifies the need for selecting a feasible research philosophy. Research philosophy refers to the thinking of the researcher related to the development of knowledge. Academic researchers (Saunders, et al., 2003; Tossy, 2016; Kautz \& Pries-Heje, 2013) have provided three leading research philosophies such as positivism, interpretivism and realism. The selection of one from the alternative is required assessing compatibility between the chosen philosophy and the research aim and objectives. The first philosophy of positivism allows the researcher to of the natural scientist (Saunders, et al., 2003). 
If selected, positivism would have allowed investigating the impacts of technologies on the workforce of manufacturing sector through quantifiable observations, independent of the perceptions or views of manufacturing employees (subjects) of the research (Saunders, et al., 2003). In contrary, the selection of realism would have led to highly objective findings, independent of human thoughts and beliefs. Realism offers value to the social forces, structures, or processes giving rise to the impacts of technological influence on the workforce future e.g. globalisation, innovation and others (Saunders \& Lewis, 2017).

Since the current investigation required focusing, specifically on the interpretations of the employees, who have or would experience the impact of technologies disrupting the manner of their working at present and in future, therefore, interpretivism was identified as feasible (Saunders, et al., 2003). Interpretivism philosophy was useful due to its consideration of the constantly changing nature of reality with the changes in people's interpretation. Hence, the focus was put on the motives, actions, and intentions of the research participants.

\section{Research Approaches}

The second layer of the research onion assesses the researcher in the selection of an appropriate research approach, which is related to the use of theory in the research. Research approach describes the design of the investigation, where the aim is to develop a theory or to test an existing theory (Saunders, et al., 2003). There are two types of approaches available such as deductive and inductive approaches. The deductive approach focuses on the development of a hypothesis based on an existing theory for testing the specific data gathered from a group of people or institutions. On the other side, the inductive approach refers to the one that helps in the development of a new theory from the data gathered and analysed in relation to a specific group of people, institutions are objects.

To maintain the compatibility between the research aim and approach, the current study has opted for the inductive theory as the study aimed to suggest a possible safety net by governments and policymakers as well as the international community necessary for the preserving the employment opportunities for the workforce. The study is based on interpretivism are more compatible with the inducting approach. It was assistive in the acquisition of an understanding of human subjects attach to events. For this reason, motivations, experience, feelings, and perceptions of the global factory sector employees were targeted through this investigation.

\section{Research Strategies}

Based on the choice of philosophies and approach, are relevant for the strategy was selected. Research strategy defined the general plan to depict how the research questions would be answered. Saunders, et al., (2003) have offered a list of research strategies along with the scope, benefits, and limitations of each strategy. These include experiment, survey, case study, grounded theory, ethnography, interviews, and action research.

Survey strategy was selected for gathering a large amount of data from the sizeable population, with low cost. A survey from the employees of global manufacturing organisations worldwide was carried out through direct contact. The face-to-face communication helped in approaching a diversified group of people of different ages, genders, experiences, and organisations. People were approached by visiting public places such as shopping malls, parks, departures of the manufacturing organisations located in the local areas. However, in contrary to the other alternatives, survey strategy is realised as more authoritative and researcher control process. Such limitations of the survey strategy would have affected the generalisation, due to the presence of bias. For this reason, the survey instrument was presented to an expert, for 
analysing the reliability and validity of the content and questions presented. On the other side, a face-to-face survey strategy was helpful in dealing with the other major limitation i.e. dependency on others for information. During face-to-face surveys, it is easy for the researcher to switch the respondents in case of no answer, incomplete answer or inappropriate answers.

\section{Time Horizons}

The fourth layer of the research onion highlighted the need to select an appropriate time of risk from the two available alternatives such as longitudinal analysis and cross-sectional analysis (Saunders, et al., 2003). The choice of one is based on related researchers plan for either taking a snapshot of the findings at a particular time through cross-sectional analysis or to create data findings capable of representing an event over a given period through longitudinal analysis.

Due to the time constraints associated with the academic course, cross-sectional time horizon was chosen for investigating the impacts of technologies on the future of the global workforce. It can be examined that survey strategy is based on cross-sectional study designs for helping the researcher in identifying the cause and effect relationship between the research variables. For this reason, the current investigation has attempted to investigate the employees, working in the manufacturing organisations worldwide, for their perceptions about the future impacts of disruptive technologies through cross-sectional designs.

\section{Data Collection Methods}

The fifth layer required the researchers to design a structured process for collecting data from the targeted research participants. Says was categorised into population and sampling, research instrument, and pilot testing (Saunders, et al., 2003).

Population and sampling assisted in withdrawing an appropriate and statistically significant number of people from the research population. Theoretically, the research population is defined as the group of people sharing similar characteristics, necessary for generalisation of the findings. To investigate the impact of disruptive technologies in the future workforce, UK employees working in the manufacturing sector made the research population. There are millions of people working in the manufacturing originations and therefore, 100-sample size was regarded as an appropriate data collection method. The chosen sample was investigated using the design research instrument.

Designing an appropriate research instrument for the survey required a robust understanding of the literature review and the available research data. The use of theoretical and practical findings gathered in chapter 2 was used to design a 20 questions-based survey instrument, containing two key sections. The first section of the instrument contained demographic details of the research respondents such as name, age, experience, gender, educational qualification, name of the manufacturing organisation, sector of the manufacturing organisation. Besides collecting these demographic details, the second section was comprised of 20 study related questions. These questions tend to investigate the most dominant types of disruptive technologies used in the manufacturing sector, the current and future impacts of such technologies on the workforce employment, the existing government policies and international communities focus on such impacts and suggestions for the way forward.

In order to test the effectiveness of the research instrument in gathering the relevant findings from the targeted respondents, a pilot test was conducted from the 10 individuals. Participants were approached on weekends outside the departures of the manufacturing factories and offices after the office hours. Due to no direct involvement of any specific manufacturing 
organisation in the investigation, no permission was necessary from the management or authorities of such organisations. The responses of the pilot study have revealed findings and substantiated the use of device instrument for conducting investigations from the remaining 90 employees. The entire data collection process lasted for two weeks.

\section{Data Analysis Methods}

Data analysis was the last layer of the (Saunders, et al., 2003) research onion. Data analysis for the survey findings was carried out employing a descriptive analysis and frequency of responses. The effectiveness of the data analysis method can be traced through its effectiveness in statistically presenting the subjective interpretations of the respondents. Furthermore, the use of charts, graphs and tables are expected to represent easily understandable things in front of the research audience. Likewise, the descriptive statistics were in the variations in the responses of different participants, which is highly necessary to suggest an effective possible safety net for the global workforce in the manufacturing sector.

\section{Research Ethics}

Ethical considerations in an academic research contributed vitally in shaping the credible research findings and conclusions. Every researcher is required to ensure that no harm, both physically as well as mentally, is imposed on the research participants (Saunders, et al., 2003). Consequently, the current investigation did look after the set of considerations for primary data respondents such as privacy and confidentiality, informed consent, voluntary participation, and originality. Likewise, in using the range of findings gathered from different secondary data sources, compliance of academic reference guidelines was made. Additionally, the reliability and validity of the data were ensured for including the up-to-date findings in the research. The methodology was designed focusing on consistency i.e. it can be easily replicated by the other researchers investigating the same phenomenon in a different context.

\section{Conclusion}

Hence, the research methodology developed using the research can be summarised indicating its effectiveness in addressing the research aim and objectives as well as in seeking answers to the research questions effectively. The interpretivism philosophy, inductive approach, survey strategy, and cross-sectional time horizons were identified as highly commendable in addressing the subjective interpretations of the employees working in the manufacturing organisations worldwide. The strengths and limitations of each of the research technological components are presented to justify its employment in the current research. All these components individually as well as collectively possessed potentials of generalising the findings over the worldwide population. Using the developed methodology, the next chapter presents the data gathered from the survey in the critical analysis of such findings.

\section{Introduction}

\section{CHAPTER FOUR: RESULTS AND FINDINGS}

The chapter presents the findings of the primary investigation gathered through a questionnaire distributed to the hundred employees working in manufacturing organisations. The chapter tends to present and critically analyse the findings in the four main categories below including demographic profile of the respondents, effects of disruptive technologies on the employment situation, impacts of technologies on production activity, and impact of technology on organisations' performances. The critical interpretation of the findings in this chapter would form the base for the subsequent discussion in the next chapter. 


\section{Questionnaire's Findings, Interpretations and Analysis Demographic Profile of the Respondents}

Assessment of the demographic profiles of the respondents in a primary investigation is highly significant for identifying the specific factors influencing the responses associated with specific investigation phenomena. Perceptions and opinions of the respondents in the manufacturing sector about the impacts of disruptive technologies can ultimately be the consequence of the age, gender, experience and positions of participants. Age is a key indicator used for measuring the maturity of the participants. More maturity refers to high experience and understandings of the disruptive technologies and their effects on the productivity and overall organisation performances. From the below-given figure, it can be depicted that out of hundred respondents more than half i.e. $59 \%$ of the respondents belonged to the age category of $26-35$ years old. In other words, a large percentage of the employees in the manufacturing sector belongs to a youth-adult category. In contrary, the percentage of young people, as well as adults and older aged individuals, was identified a relatively very low $(11 \%, 17 \%$ and $13 \%)$. Academic researchers have substantiated this point by indicating the effects of emerging disruptive technologies on the rising perceptions of the youth towards self-employment and remote working opportunities, rather than selecting full-time jobs in traditional employment sectors such as agriculture and manufacturing (Palfrey \& Gasser, 2011).

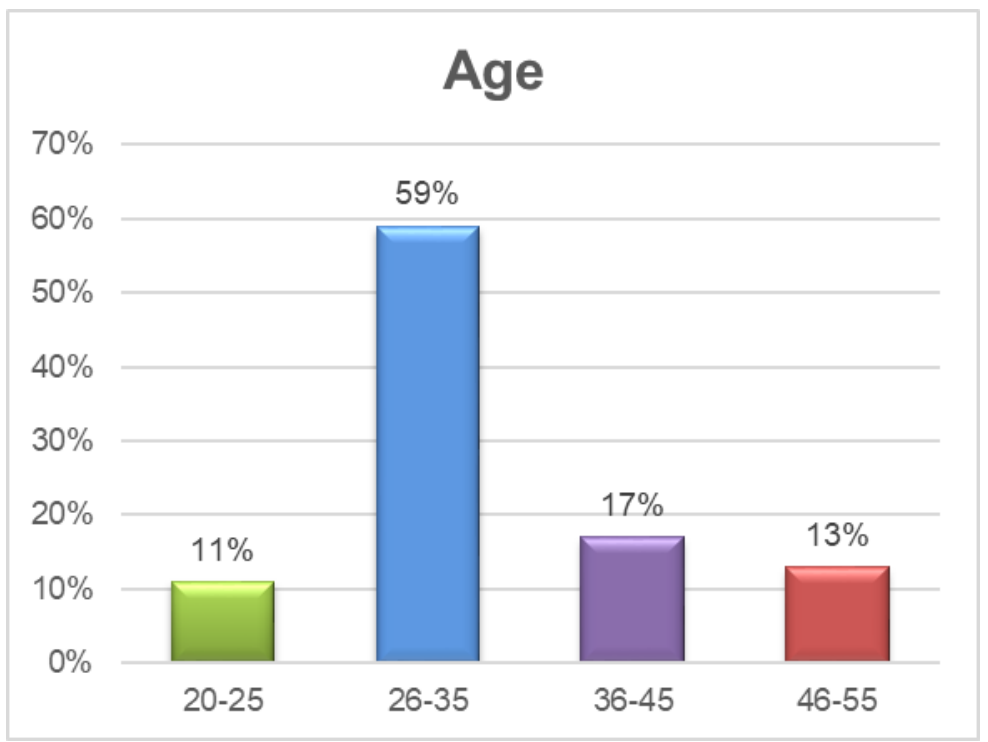

Figure 4.2-1: Questionnaire Respondents' Age

Furthermore, the analysis of the gender reveals that a large percentage of the respondents in the manufacturing sector belongs to the male category (69\%). Comparatively, only $31 \%$ of the females responded to the questionnaire. Such differences in the male and female can be attributed to the two reasons. Firstly, such results highlight gender discrimination being practised within the manufacturing sector worldwide. Secondly, there is a possibility that females are less motivated towards the sector due to the technicalities and physical stressing work involved in manufacturing activities. 


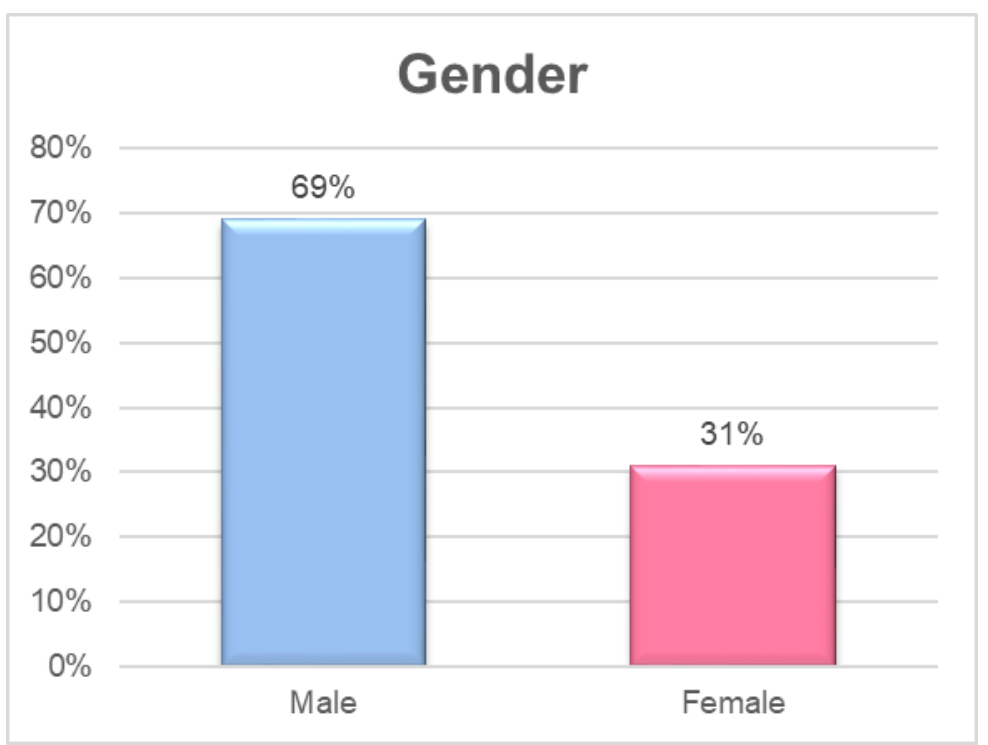

Figure 4.2-2: Questionnaire Respondents' Gender

Moreover, the findings gathered for the experiences of the respondents in the company further revealed that a large percentage of the respondents have five years' experiences (35\%) and 10 years' experience (26\%), while none of them had more than 20 years' experience $(0 \%)$. Probably, the individuals having more experience in the sector are reluctant and resistant to a new change and prefer to work according to the standard patterns. On the other side, more experience can also be attributed to the enhancement of skills and competencies according to the changing market circumstances. Therefore, the inclusion of more experienced individuals in the questionnaire survey would ultimately help in gaining perceptions of the experienced employees regarding the current and foreseen effects of disruptive technologies in future.

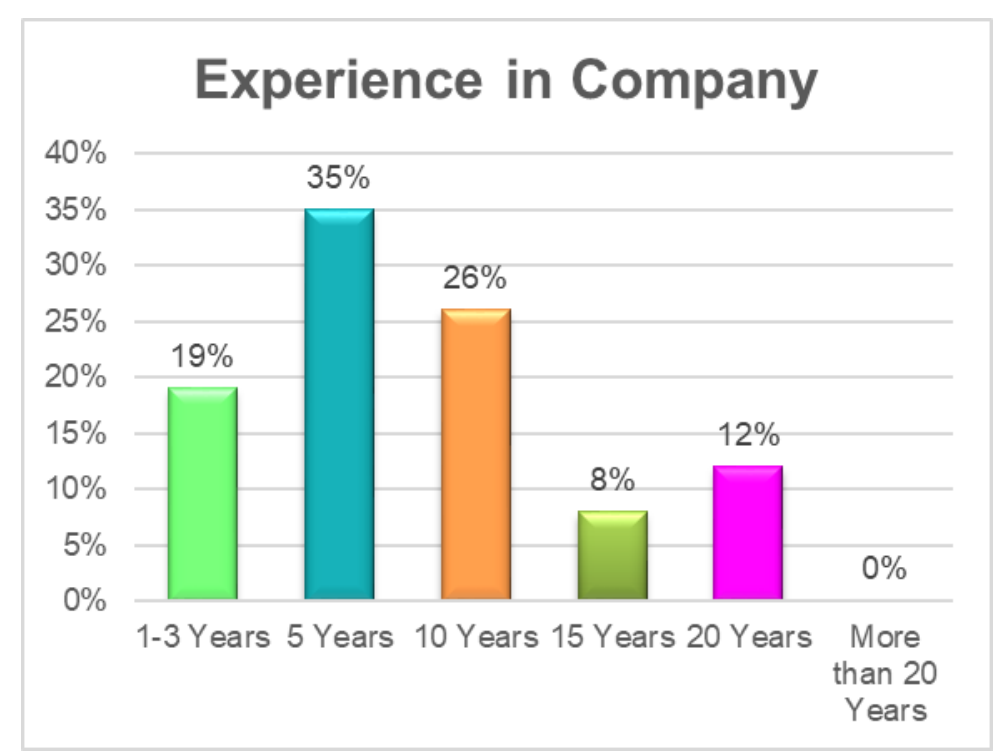

Figure 4.2-3: Questionnaire Respondents' Experience

Likewise, understanding the positions of the respondent in the manufacturing sector was also essential to evaluate their findings. It is generally assumed that the management level the individuals have different problems and challenges compared with operational and production level people (Betz, 2011). Results in Figure 4.2- 4 below as highlighted that $67 \%$ of the respondents belonged to the production worker category while only $3 \%$ belonged to the management side. 


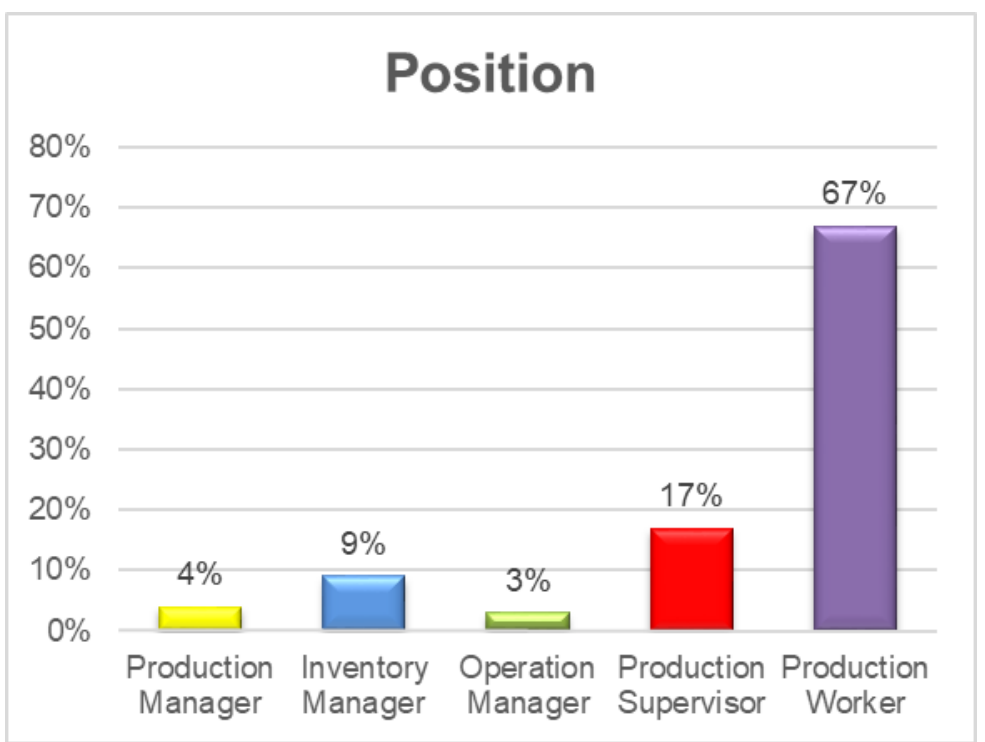

Figure 4.2-4: Questionnaire Respondents' Position

Subsequent to the interpretation of demographic factors-findings, the next sections of the results discuss the findings gathered effects of disruptive technology on the employment situation, production activity and organisations performances.

\section{Effects of Disruptive Technologies on Employment Situation}

For assessing the effects of disruptive technologies on the employment situation, six different statements were developed and investigated from 100 respondents from the manufacturing sector. Initially, it was necessary to inquire about the presence of disruptive technology has been introduced within their companies. Exposure to the recent technology is probable to have a more in-depth understanding of the effects of such technologies in an employment situation. Findings of the figures given below revealed a cumulative agreement from the respondents (Strongly Agree = 32\%, Agree = 29\%).

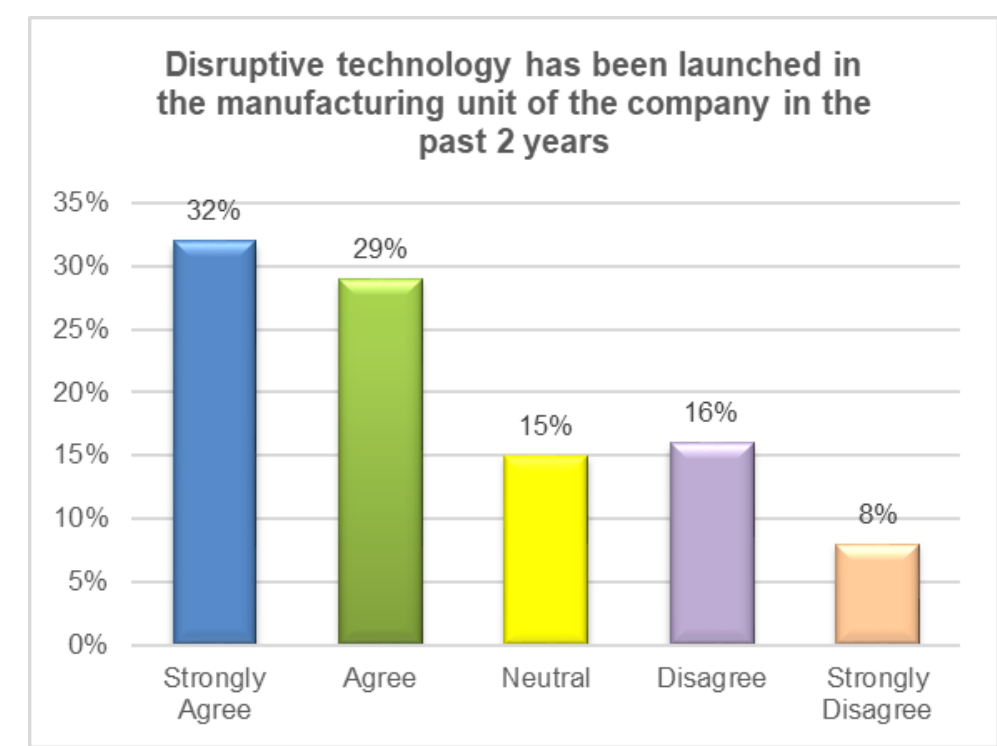

Figure 4.2-5: Presence of Disruptive Technologies in Manufacturing Company

Examination of another effect was extremely indispensable for the current investigation to evaluating whether the disruptive technologies are directly or indirectly affecting staffing and HR. Positive results were gathered indicating 41\% strong agreement and $11 \%$ agreement to positive in staffing of new employees related with the disruptive technologies. However, 25\% 
of the cumulative segment can also not be undermined while assessing the effects of technologies.

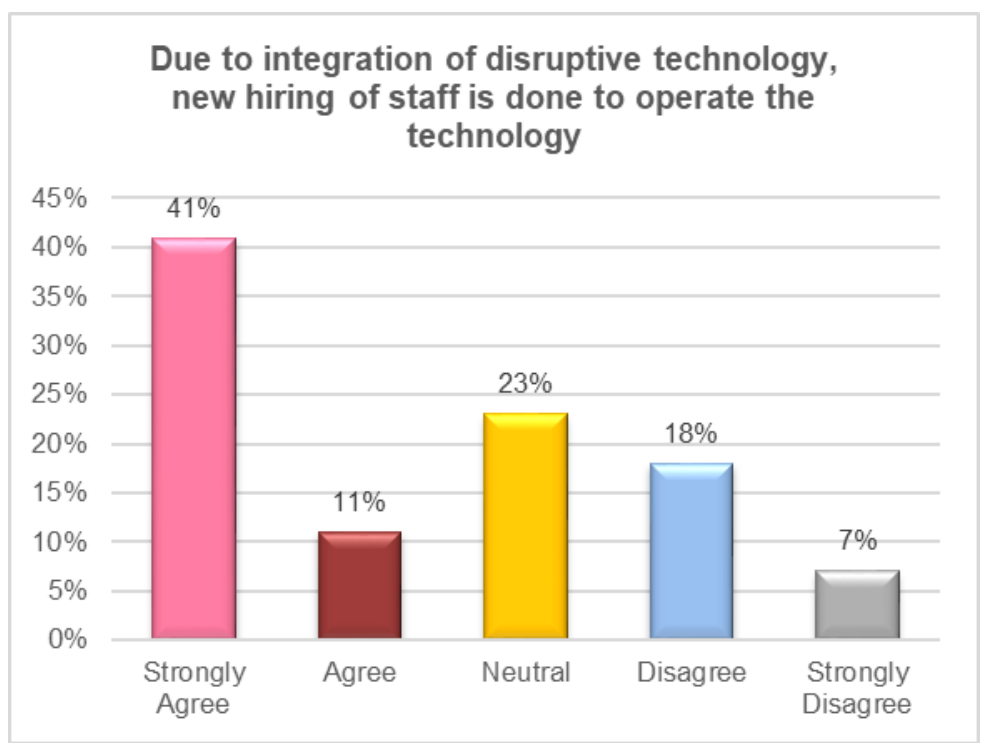

Figure 4.2-6: Effects of Staff Hiring to Operate the Technology

Moreover, participants were also enquired about the effects of disruptive technologies or increased training of the existing employees. Unfortunately, a very low percentage was received in response to the statement, i.e. strongly agree $=12 \%$ and agree $=19 \%$. Specifically, a large percentage of the respondents (47\%) gave neutral responses, ultimately highlighting their ignorance associated with this question.

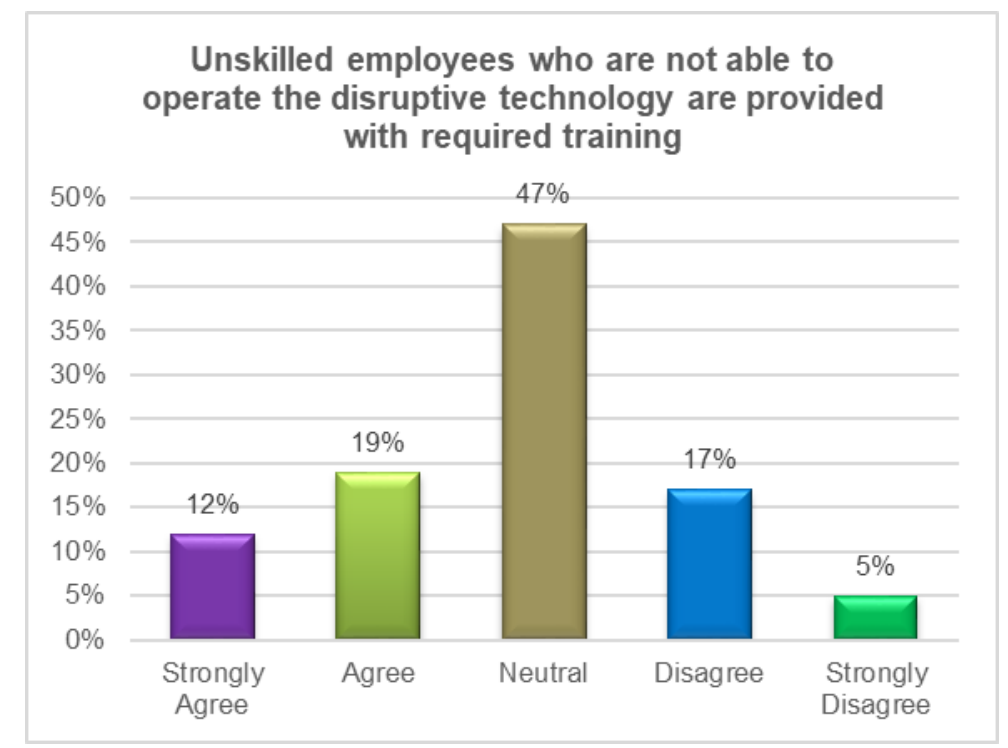

Figure 4.2-7: Provision of Unskilled Employees' Training

Additionally, the next question has highlighted the manufacturing staff due to the integration of disruptive technology. The 33\% strong agreement and $49 \%$ agreement have confirmed that the workforce of the manufacturing units is decreasing. However, these findings are in contradictory with the figure $4.2-6$, where $41 \%$ strongly agree and $11 \%$ agree to the positive effects of technology on increasing the staff of the organisation. The likely reason behind such discrepancies between the responses gathered for the two statements can be attributed to the employers' focus on hiring skilled and talented employees capable of dealing with the 
disruptive technologies launched only. On the other side, the employers in the manufacturing sector might be firing the unskilled workers.

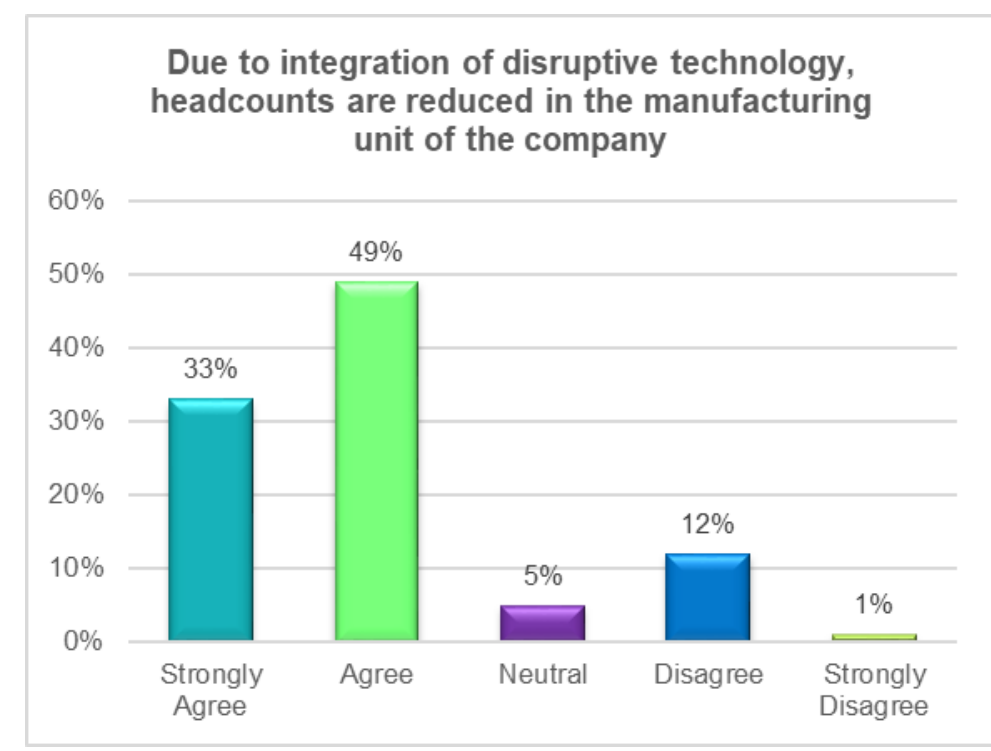

Figure 4.2-8: Staff Hiring to Operate the Technology

Furthermore, findings gathered in the figure 4.2-9 have depicted that a large percentage of the respondents have agreed to the rising unrest among employees with the integration of the disruptive technologies (strongly agree $=31 \%$ and agree $=43 \%$ ). Most of them, the presence of technology in their manufacturing unit is the indicator of their replacement with the robots in future.

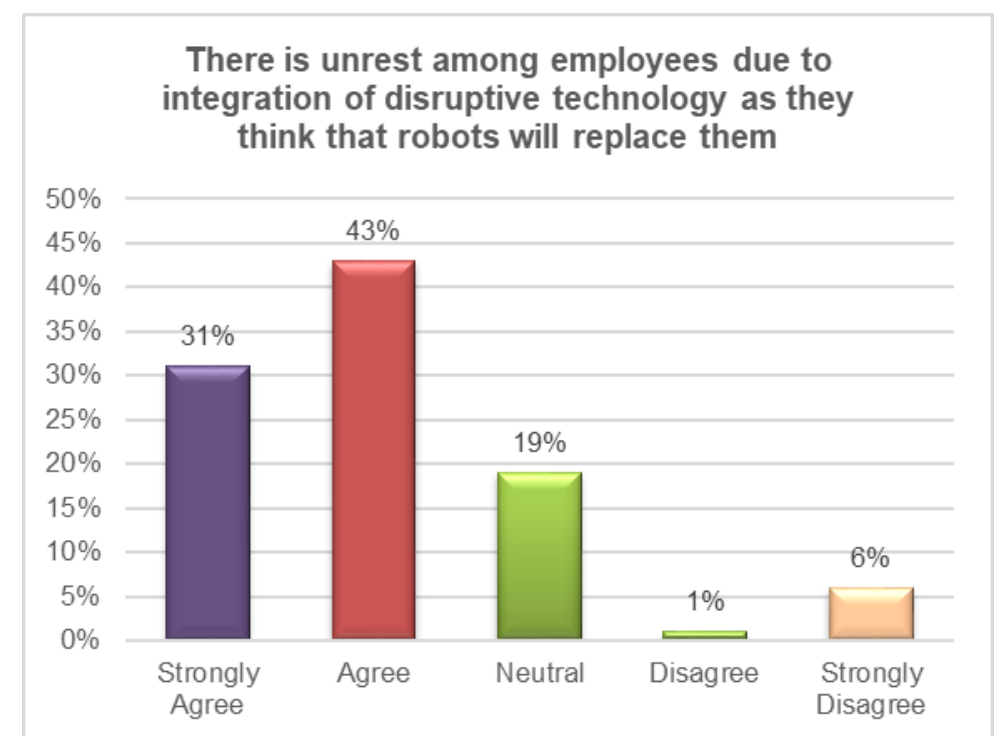

Figure 4.2-9: Technology's Role in Replacing Staff with Robots

The last statement in this section was keen to inquire about the effects of disruptive technologies on the rise in pay scales of employees in the manufacturing unit. Unexpectedly, the strong disagreement was gathered where $46 \%$ disagree and $26 \%$ strongly disagree with the pay based positive impacts. 


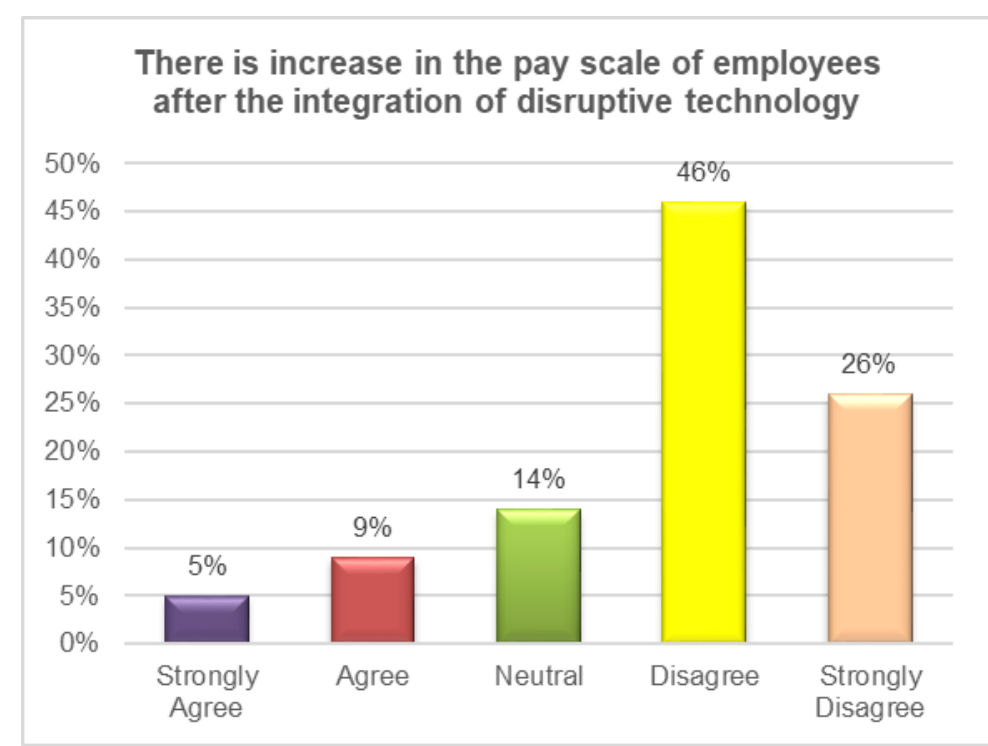

Figure 4.2-10: Effects of Disruptive Technology on Pay-based Compensation

\section{Impacts of Technologies on Production Activity}

Besides, the impacts of disruptive technologies and production activity were also assessed through the questionnaire. Set of six statements included in this section, the main aim behind which was to assess to what extent the new technologies are affecting the production activities within the manufacturing unit.

The findings given in the figure below has shown 36\% strong agreement and 25\% agreement from the 100 respondents, who have collectively acknowledged the effects of technology in producing more quality products within their organisation.

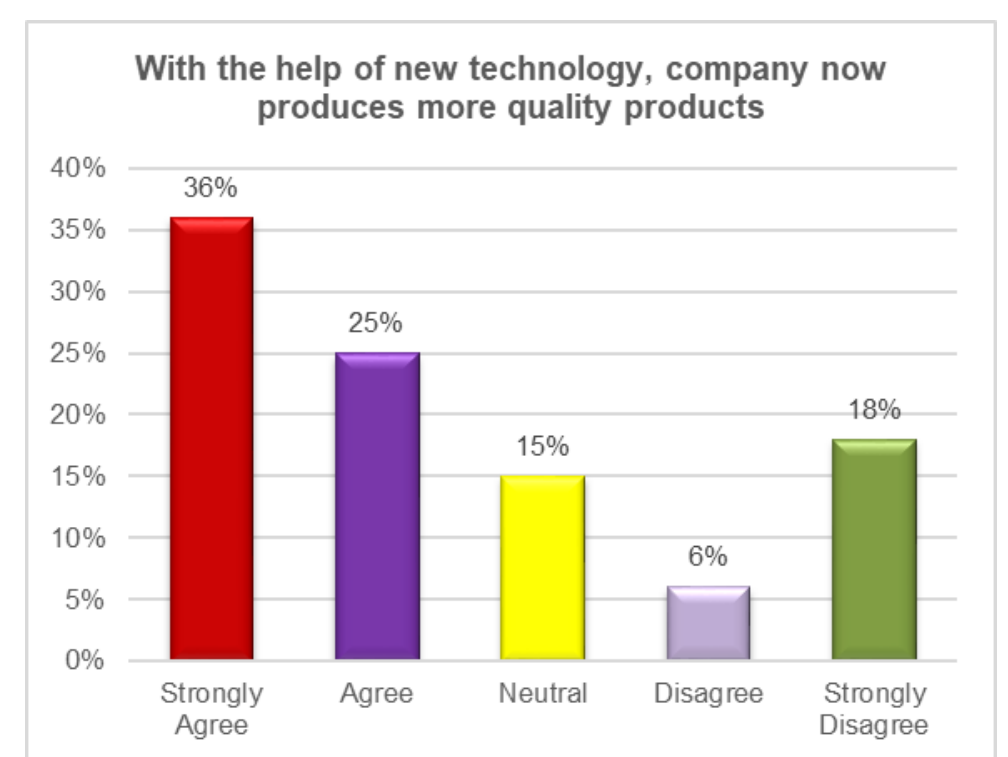

Figure 4.2-11: Effects of Disruptive Technology on Production of Quality Products

Likewise, besides quality, new disruptive technologies are capable of increasing the overall production output for the manufacturing companies. With 23\% strong agreement and $17 \%$ agreement, a large percentage of the respondents did agree to the fact. However, $39 \%$ of the respondents remained neutral in their responses. 


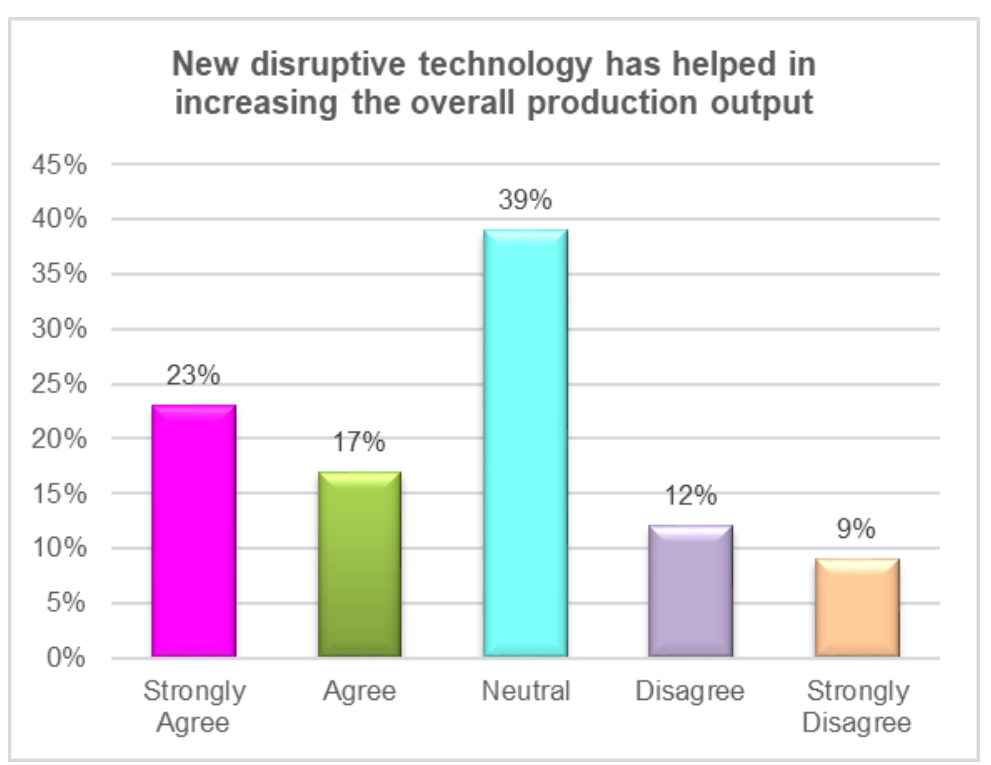

Figure 4.2-12: Effects of Disruptive Technology on Pay-based Compensation

Another question was designed to inquire about the effects of disruptive technology in improving the manufacturing process. Unexpectedly, only $14 \%$ of the respondents out respondents agreed to the favourable impacts, while 52\% remained neutral in discussing any impact and 34\% cumulatively disagreed. It is quite considerable for the manufacturing organisations to view that the new technologies are not the effects of improving their production process. They should identify the factors shaping such effects.

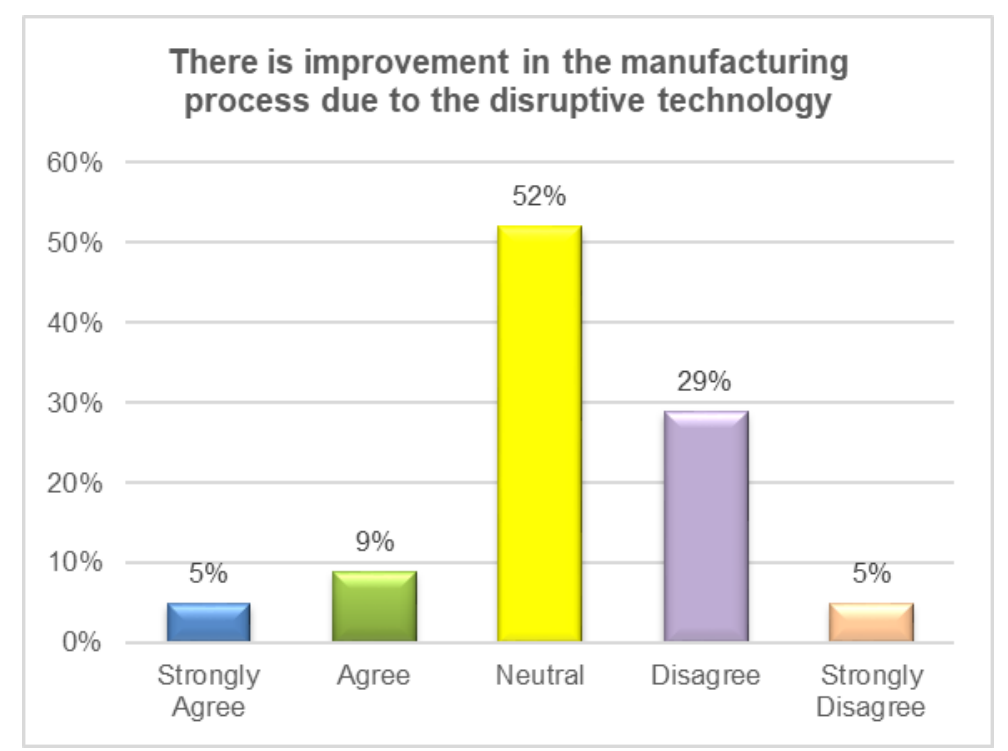

Figure 4.2-13: Effects of Disruptive Technology on Manufacturing Process

However, one of the significant effects of disruptive technologies was identified in connectivity with the reduced production costs. Out of the respondents, $13 \%$ strongly agree and 29\% agree to the statement. 


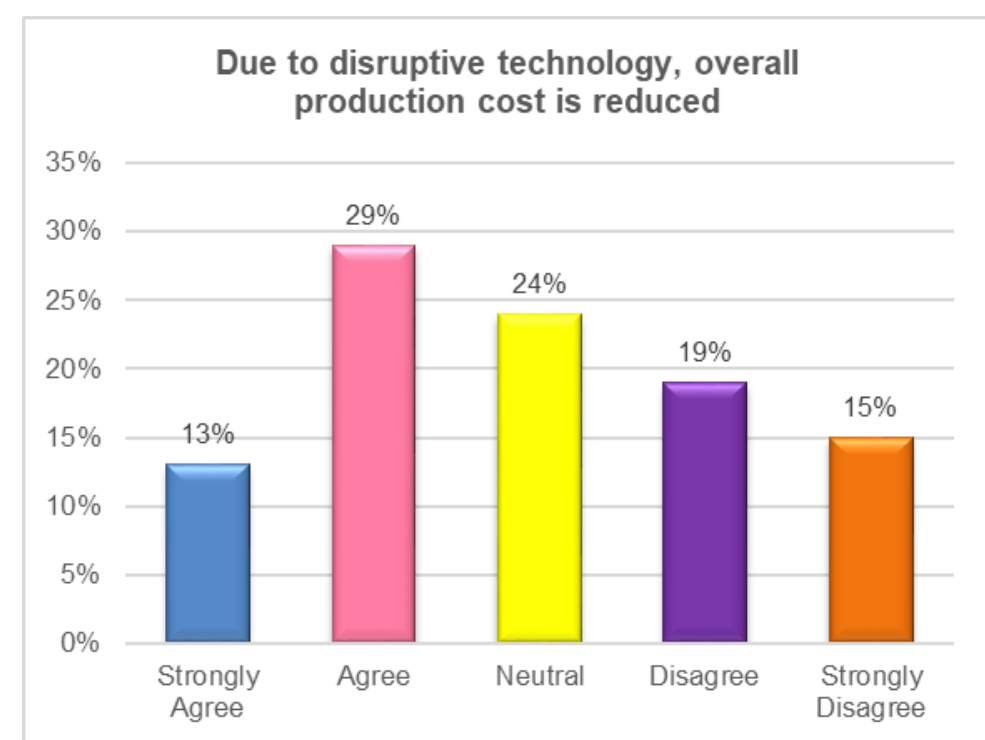

Figure 4.2-14: Effects of Disruptive Technology on Production Cost

Currently, the manufacturing unit has attempted to overcome the cost of production delays with the use of disruptive technologies. Overall, $20 \%$ of the respondents strongly agree and $22 \%$ agree to the statement. Generally, cost of delays in production yields relatively higher risks for the business, compared to the normal cost of production. Delay can place significant impacts on the overall accomplishment of the scope, schedule and budget.

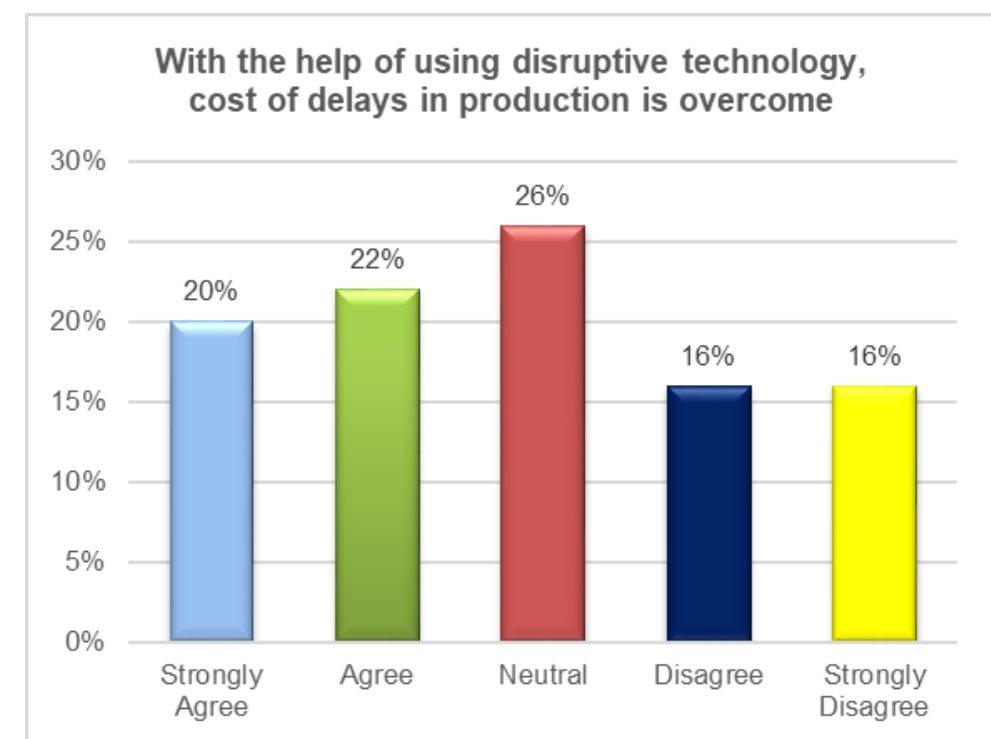

Figure 4.2-13: Effects of Disruptive Technology on Cost of Delays in Production

Likewise, there is a statement assessing the impacts of the disruptive technology of production activity was related to the waste management aspects. The findings revealed that new technologies have not significantly contributed to the proper management of the waste in the manufacturing unit. Only 15\% strongly agree and 19\% agree to the statement. 


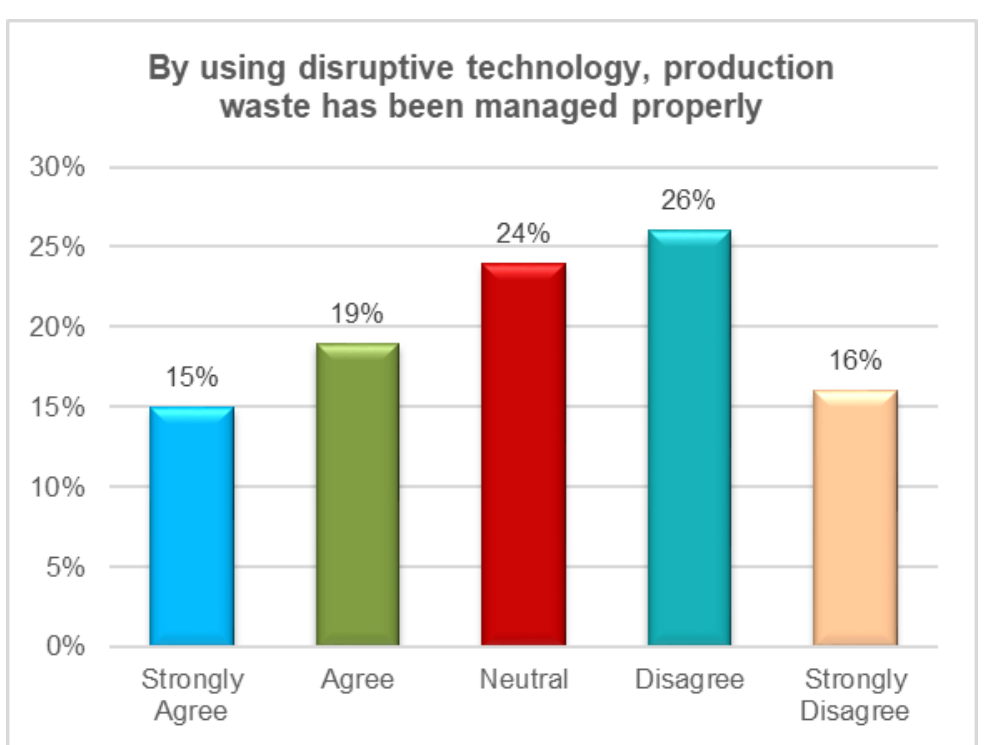

\section{Figure 4.2-16: Effects of Disruptive Technology on Production Waste}

It is quite a considerable fact in the findings gathered from the questionnaire that the high percentage of the respondents are either neutral or have a disagreement for disruptive technologies in the production activity. Subsequently, the next section of the chapter presents and discussed the impacts of technology on organisations 'performance overall.

\section{Impact of Technology on Organisations' Performances}

Three statements were developed for identifying the impacts of technology on the overall organisational performances. Figure 4.2 - 17 has revealed that a large percentage (strongly agree $=29 \%$ and agree $=32 \%$ ) favoured the statement that disruptive technologies have helped in improving the organisation's performances. On the other side, $28 \%$ cumulative disagreement can also not be underestimated.

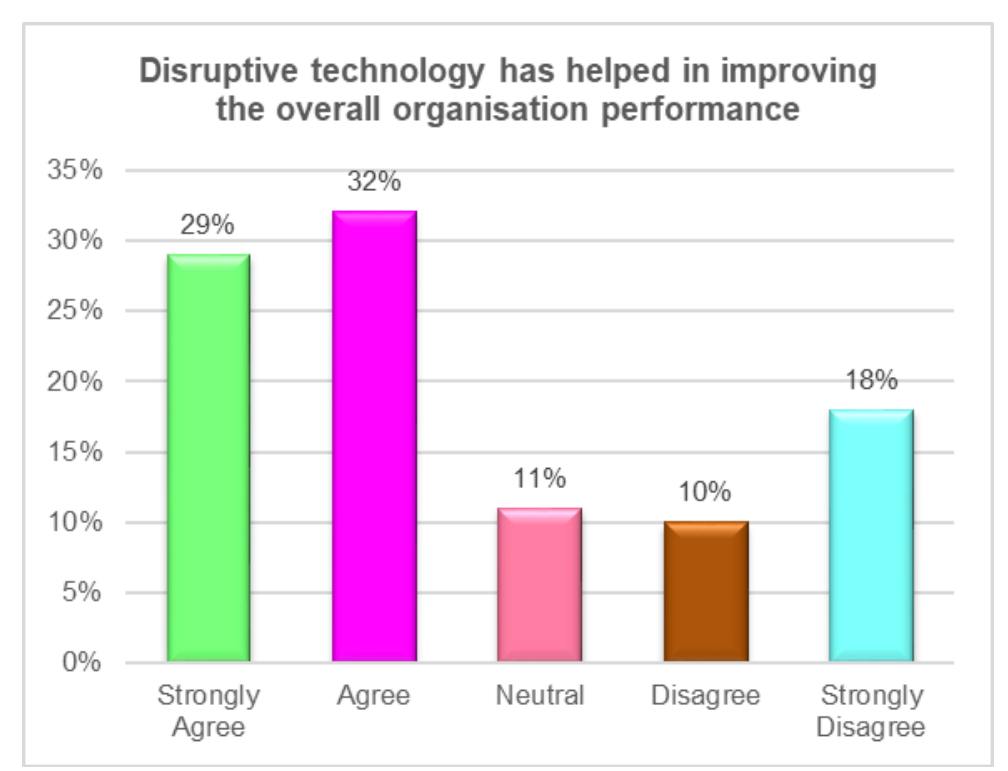

Figure 4.2-17: Effects of Disruptive Technology on Overall Organisation Performance

Similarly, a strong agreement (strongly agree $=35 \%$ and agree $=27 \%$ ) was received for the effects of disruptive technology on the high organisation profits. 


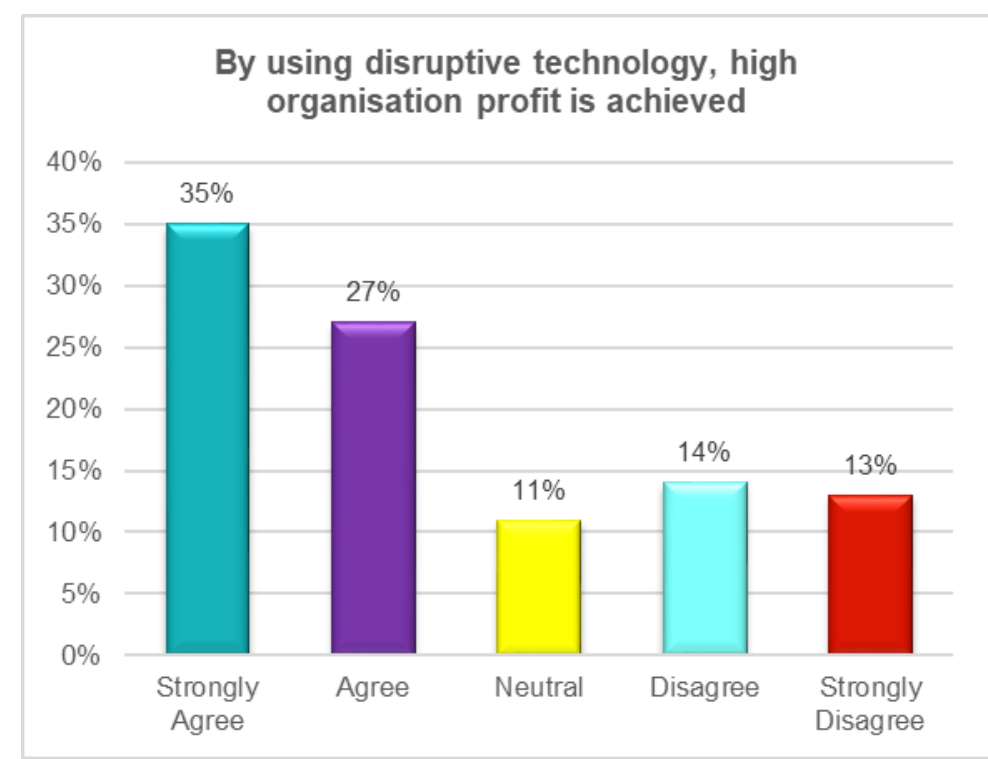

Figure 4.2-18: Effects of Disruptive Technology on High Organisation Profits

Lastly, mixed responses were gathered for identifying the effects of technology on the reliability and consistency of the organisation growth. Both the strong agreement and strong disagreement have depicted the same percentage (25\%).

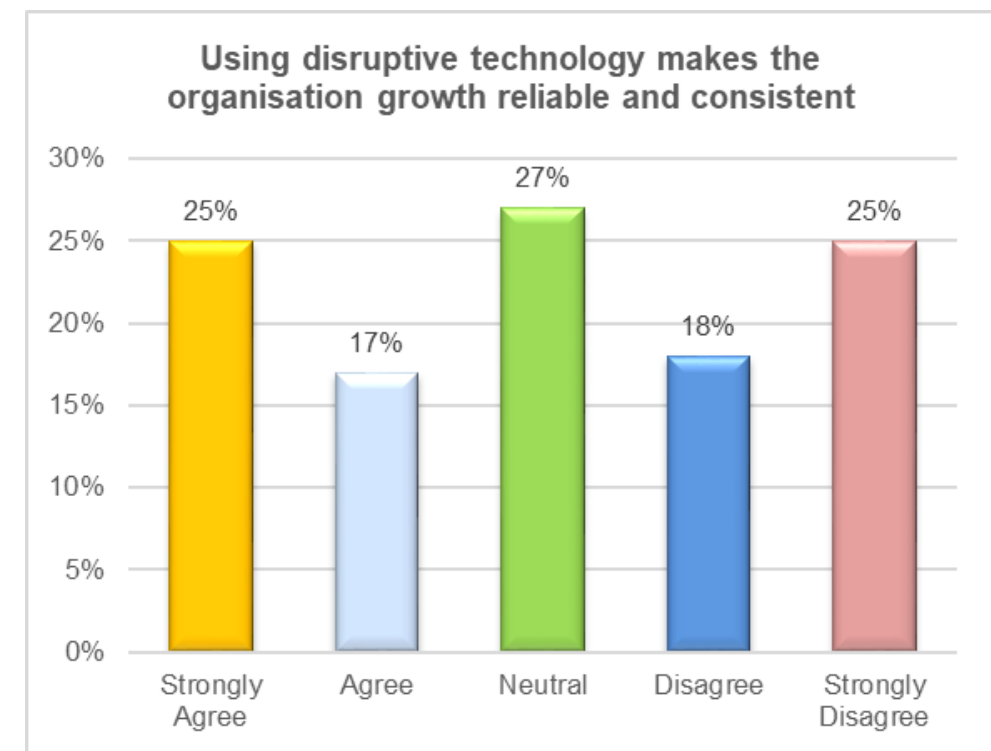

Figure 4.2-19: Effects of Disruptive Technology on Reliable and Consistent Organisation Growth

\section{Conclusion}

Hence, the findings analysed in the chapter has depicted that effects of disruptive technologies are positively inclined towards the production activity and overall organisation performances in the manufacturing organisation but on the other side, these technologies are examined as negatively affecting the employment situation. The next chapter presents a discussion on the primary and secondary data findings.

\section{Introduction}

\section{CHAPTER FIVE: DISCUSSION}

The chapter presents a discussion based on research objectives on the findings gathered from the literature review and questionnaire conducted from the primary respondents. The aim is to compare these findings for the identification of similarities and differences, which can 
ultimately help in shaping out the possible safety net for the workforce in the manufacturing organisations in future.

\section{Discussion based on Research Objectives}

Both the literature review and primary investigation have in the accomplishment of research objectives set in the introduction chapter.

Research Objective \# 1: To investigate the current and possible future impacts (over 5 to 10) of disruptive technologies on the global workforce displacement in the manufacturing sector

One side, academic researchers (Armstrong, 2017; Manyika, et al., 2013; Ekekwe, 2012) have acknowledged the power of disruptive technology shaking the entire industry and setting out new standards, on the other side primary respondents have also substantiated the positive and negative impacts of these technologies on the employment situation, production activity, and on the overall organisational performance. The range of disruptive technologies such as 5G, artificial intelligence, machine learning, robots and others are affecting the working of employees within the manufacturing organisations, and replacement and job loss for the workers. Responses gathered under three categories such as employment situation, production activity, and overall organisational performance have substantiated the literature findings, indicating the effects of digitalisation and automation on the human resource management, communication planning, production cycle, and financial sides of the manufacturing units (Walker, 2018). The current study has assisted in identifying the most affected department with the manufacturing companies is the production workers' units. According to them, technology has responsibilities along with the threat of job loss and displacement. They further highlighted that despite the management of the manufacturing company is focusing on integrating new disruptive technologies for easing quality products, production output and reducing the cost of delays and waste management, yet their employers do not consider the need to train and equip employees with the required skills. For this reason, the employment situation is turning out as adverse for the unskilled workers. In fact, the manufacturing employers have started recruiting talented and employees, against the reduced headcount of the production workers (Arntz, et al., 2016). The respondents enquired confirmed the negative the effects of integrating new disruptive technologies in the recruitment of new staff. Much of the focus of organisations employers is towards the cost reduction using disruptive technologies rather than compensating the affected workers (BenediktFrey \& A.Osborne, 2017). However, the respondents' findings are in conjunction with the findings of the literature where academic researchers have substantiated the rise in technological usage within the manufacturing sector, capable of leading to enhanced qualitybased productivity. The manufacturing companies are able to produce more quality products compared to the past (Betz, 2011).

\section{Research Objective \# 2: To evaluate the current policy measures available for the protection of the global workforce}

Not many policy measures are available for the protection of the international workforce in the manufacturing sector from the resulting effects of the disruptive technologies. Academic researchers (Arntz, et al., 2016; ET Online, 2017; Paul \& Siegel, 2001) have highlighted the significance given to training opportunities by the OECD and other global authorities as a driving force behind the learning and development of employees and to protect them from technology-directed displacements. However, such training needs to be aligned with the needs of their workers and not simply like the current one designed in general and with a profitable initiative for the manufacturing employers only, as confirmed by respondents. Likewise, in some of the global organisations, compensatory policies are given significant worth. 
Compensation based effects are highly important within the literature as compensation has the power to affect positively or negatively the employees' productivity and the overall organisation's performance (Mehta, 2016). However, none of such policies is directed to identify the impacts of new disruptive technologies on the need to modify labour composition as considered indispensable by the (Paul \& Siegel, 2001).

\section{Research Objective \# 3: To suggest a possible safety net for governments and policymakers as well as the international community for balancing technology disruption impacts for workforce}

The primary investigation has shown more neutral and disagreement-based responses from the employees in the manufacturing units. Such responses indicated that the disruptive technology launched within the manufacturing unit of the company is still in its initial stage with lots of improvement needed, to direct impacts on the overall quality, production output, production processes and production costs.

Therefore, governments and policymakers need to consider creating a possible safety-net based on the given recommendations.

- Firstly, the mandatory training regulations should be enforced, oblige the manufacturing organisations to train their existing workforce about the new launch disruptive technologies.

○ When these disruptive technologies are designed to work like humans, similarly humans should be trained to gain understanding about how these technologies work.

- Secondly, compensation based regulations should be introduced to align the pay and rewards for the workers their efforts put in enhancing skills for new disruptive technologies.

$\circ$ The regulation should emphasise on the effects of disruptive technologies in increasing the mental exertions of the workers along with the decrease in their physical efforts. Compensation decrease cannot be justified with a decrease in physical work.

- Lastly, technologies should be integrated with the different production stages to increase its effects of more recruitment and staffing such as factory work, quality management, waste management, cost management and others.

O New technologies should be directed to increase new workforce along with the training of existing workforce rather than their displacement.

\section{Conclusion}

Hence, the discussion has summarised several similarities between the primary and secondary evidence gathered in this dissertation. Lack of effective policy was identified as the major reason behind the adverse effects of disruptive technologies on the employment situation, production activity and overall organisational performances. However, through the implementation of the suggested recommendations, manufacturing companies are able to control the adverse effects in the next 5 to 10 years. The last chapter of the dissertation presents the conclusion of the study.

\section{Introduction}

\section{CHAPTER SIX: CONCLUSION}

The chapter of the dissertation has summarised the key insights gathered in different chapters to show the successful accomplishment of the research aim and objectives. Besides, the path towards future research is also incorporated. 


\section{Research Conclusion}

The aim of the study was to evaluate the future of the global workforce aligned with the disruption in the manufacturing industry. The impacts of 5G, robotics, artificial intelligence, and machine learning were focused in current research, with their collective impact on the employment situation, production activity in our organisation performance of the manufacturing unit workers. Most of the workers have perceived the new disruptive technologies in workers' displacement, decreasing staffing, decreasing pay-scale, increasing unrest, and increasing the skills gap among the workers. Another site, these technologies have improved production quality, production output, waste management, and cost of delays. The effects of technologies and overall organisational performance were also identified as positive. In other words, due to lack of policy and effective regulations, these technologies are merely placing adverse effects on the human resource only. Besides favourable impacts on the processes and procedures resulting from the introduction launch of new technologies, the organisations focus on accommodating the worker's needs too. Certainly, with the fear of job loss and set of displacements, production workers productivity performances are subjected to decline passage of time and on the other side, skilled workers' expectations related with compensation and flexibility and consistency of work would raise. Therefore, there is a strong need to maintain balance in the composition of the workforce i.e. skilled and unskilled workers. This is so because technologies are ever-changing and with every change, the organisations going for the hiring of new talented workers would ultimately end up with a sustainable loss in future. In contrary, the organisations preferring adequate training and development and provision of appropriate compensation would be able to maintain their production cost as well as overall performance. Talent management through training is highly profitable relative to the continuous hiring and firing of the workers, with every change in the new technology.

Hence, with these conclusions, the overall aim and objectives were successfully accomplished.

\section{The path towards Future Research}

The findings of the current investigation can be substantiated in the subsequent research based on in-depth interviews of the manufacturing sector employers from different parts of the world. Such communication would assist in gathering insights related to the challenges and opportunities available to the manufacturing companies in the presence of new emerging disruptive technologies. Open-ended interviews are capable of extracting influence of contextual factors and environmental factors on the shaping of negative and positive effects of technologies. Furthermore, subsequent research can be directed to investigate the effects of disruptive technologies on nonmanufacturing business industries and sectors.

\section{References}

Abri, A. G. \& Mahmoudzadeh, M., 2015. Impact of information technology on productivity and efficiency in Iranian manufacturing industries. Journal of Industrial Engineering International, 11(1), pp. 143-157.

Armstrong, P., 2017. Disruptive Technologies: Understand, Evaluate, Respond. s.l.:Kogan Page.

Arntz, M., Gregory, T. \& Zierahn, U., 2016. The Risk of Automation for Jobs in OECD Countries A COMPARATIVE ANALYSIS. s.l. OECD.

Autor, D. H., Dorn, D. \& Hanson, G. H., 2015. Untangling Trade and Technology: Evidence from Local Labour Markets. The Economics Journal, 125(584), pp. 621-646.

BenediktFrey, C. \& A.Osborne, M., 2017. The future of employment: How susceptible are jobs to computerisation?*. Technological Forecasting and Social Change, Volume 114, pp. 254-280.

Benyoucef, L. \& Grabot, B., 2010. Artificial Intelligence Techniques for Networked Manufacturing Enterprises Management, s.l.: Springer Science \& Business Media.

Betz, F., 2011. Managing Technological Innovation: Competitive Advantage from Change, s.l.: John Wiley \& Sons. 
Cheng, J., Chen, W., Tao, F. \& Lin, C.-L., 2018. Industrial IoT in 5G environment towards smart manufacturing. Journal of Industrial Information Integration, Volume 10, pp. 10-19.

Chui, M., Manyika, J. \& Miremadi, M., 2016. Where machines could replace humans-and where they can't (yet). McKinsey Quarterly, July.

Daugherty, P. R. \& Wilson, H. J., 2018. Human + Machine: Reimagining Work in the Age of AI, s.l.: Harvard Business Review Press.

Durakbasa, N. M. \& Gencyilmaz, M. G., 2018. Proceedings of the International Symposium for Production Research 2018. s.l.: Springer.

Ekekwe, N., 2012. Disruptive Technologies, Innovation and Global Redesign: Emerging Implications: Emerging Implications. Hershey, PA: IGI Global.

ET Online, 2017. Layoffs scare is real, not exaggerated, finds ET's Jobs Disruption survey. Economic Times, 01 June.

European Union, 2017. Current and Emerging Trends in Disruptive Technologies: Implications for the Present and Future of EU's Trade Policy, s.l.: EP/EXPO/B/I NTA / 2017 / 06 EN.

Grandinetti, L., 2013. Pervasive Cloud Computing Technologies: Future Outlooks and Interdisciplinary Perspectives: Future Outlooks and Interdisciplinary Perspectives. s.l. IGI Global.

Jeffery, R., 2017. At Toyota, The Automation Is Human-Powered. Fast Company, 09 May.

Karsten, J. \& West, D. M., 2015. How robots, artificial intelligence, and machine learning will affect employment and public policy. Brookings.Edu, 26 October.

Kautz, K. \& Pries-Heje, J., 2013. Diffusion and Adoption of Information Technology: Proceedings of the first IFIP WG 8.6 working conference on the diffusion and adoption of information technology, Oslo, Norway, October 1995. s.l.: Springer.

Kolberg, D. \& Zühlke, D., 2015. Lean Automation enabled by Industry 4.0 Technologies. IFAC-PapersOnLine, 48(3), pp. 1870-1875.

Latif, S., Qadir, J., Farooq, S. \& Imran, M. A., 2017. How 5G Wireless (and Concomitant Technologies) Will Revolutionize Healthcare?. Future Internet, 9(4), p. 93.

Manyika, J. et al., 2013. Disruptive technologies: Advances that will transform life, business, and the global economy, s.l.: McKinsey Global Institute.

Manyika, J. et al., 2013. Disruptive technologies: Advances that will transform life, business, and the global economy. McKinsey Global Institute, May.

Marchetti, N., 2014. Towards the 5th Generation of Wireless Communication Systems, s.l.: Trinity College Dublin, Ireland.

McKinsey Global Institute, 2017. Jobs Lost, Jobs Gained: Workforce Transitions In A Time Of Automation. s.l.: McKinsey Global Institute.

Mehta, S., 2016. Innovation and Employment: A Study of Indian Manufacturing Sector. Millennial Asia, 7(2).

Mellor, S., Hao, L. \& Zhang, D., 2014. Additive manufacturing: A framework for implementation. International Journal of Production Economics, Volume 149, pp. 194-201.

OECD, 2018. Transformative technologies and jobs for the future, s.l. MONTREAL, CANADA.

Osseiran, A., Monserrat, J. F. \& Marsch, P., 2016. 5G Mobile and Wireless Communications Technology. Cambridge: Cambridge University Press.

Palfrey, J. G. \& Gasser, U., 2011. Remote Work and Collaboration: Breakthroughs in Research and Practice: Breakthroughs in Research and Practice, s.l.: ReadHowYouWant.com.

Paul, C. J. M. \& Siegel, D. S., 2001. The Impacts of Technology, Trade and Outsourcing on Employment and Labor Composition. The Scandinavian Journal of Economics, 103(2), pp. 241-264.

Poole, D. L. \& Mackworth, A. K., 2017. Artificial Intelligence. New York: Cambridge University Press.

Quora, 2018. Technology Has Already Taken Over 90\% Of The Jobs Humans Used To Do. Forbes.Com, 18 January.

Rendall, M., 2016. Industrial Robots will replace manufacturing jobs and that a good thing. Tech Crunch, 10 Oct.

Rigby, R., 2016. Job cuts and disruption call for sensitive leadership. Financial Times, 26 February.

Rosen, R. J., 2015. In Praise of Short-Term Thinking. The Atlantic.Com, 03 September. 
Sandle, T., 2018. Austria uses 5G technology to improve production. Digital Journal, 24 March.

Saunders, M. N. K. \& Lewis, P., 2017. Doing Research in Business and Management. s.l.: Pearson.

Saunders, M. N. K., Lewis, P. \& Thornhill, A., 2003. Research Methods for Business Students. s.l.: Pearson.

Shin, D.-I., 2017. An exploratory study of innovation strategies of the internet of things SMEs in South Korea. Asia Pacific Journal of Innovation and Entrepreneurship, 11(2), pp. 171-189.

Shi, Z., 2011. Advanced Artificial Intelligence. s.l. World Scientific.

Shrek, J., 2010. Technology Explains Drop in Manufacturing Jobs. The Heritage Foundation, 12 October.

Spiegel, R., 2018. Robots Are Displacing Manual Labor Jobs. DesignNews, 08 February.

Tarantola, A., 2017. Teaming humans with robotic AI will remake modern manufacturing. Engadget, 19 August.

Thames, L. \& Schaefer, D., 2017. Cybersecurity for Industry 4.0: Analysis for Design and Manufacturing. s.l.: Springer.

Tossy, T., 2016. Information Technology Integration for Socio-Economic Development. s.l. IGI Global.

Walker, J., 2018. Machine Learning in Manufacturing - Present and Future Use-Cases. Tech Emergence, 29 May.

Wang, L. \& Wang, X. V., 2017. Cloud-Based Cyber-Physical Systems in Manufacturing. s.l.: Springer.

Wang, S. et al., 2016. Towards a smart factory for industry 4.0: a self-organized multi-agent system with big databased feedback and coordination. Computer Networks, 101(4), pp. 158-168.

Wang, X. V., Wang, L., Mohammed, A. \& Givehchi, M., 2017. Ubiquitous manufacturing system based on Cloud: A robotics application. Robotics and Computer-Integrated Manufacturing, Volume 45, pp. 116-125.

West, D. M., 2016. What happens if robots take jobs? The impact of emerging technologies on employment and public policy. Center for Technology Innovations at Brookings, pp. 1-22.

Xiang, W., Zheng, K. \& Shen, X. (., 2016. 5G Mobile Communications. s.l.: Springer.

Yang Yang, J. X., Shi, G. \& Wang, C.-X., 2017. 5G Wireless Systems: Simulation and Evaluation Techniques. s.l.:

Springer. 


\section{Profile}

\section{APPENDIX - QUESTIONNAIRE INSTRUMENT}

1. Name

2. Gender

3. Age

4. Position

5. Experience in current company

\section{Effect on the employment situation}

6. Disruptive technology has been launched in the manufacturing unit of the company in the past 2 years.

7. Due to the integration of disruptive technology, the new hiring of staff is done to operate the technology.

8. Unskilled employees who are not able to operate the disruptive technology are provided with required training.

9. Due to the integration of disruptive technology, headcounts are reduced in the manufacturing unit of the company.

10. There is unrest among employees due to the integration of disruptive technology as they think that robots will replace them.

11. There is an increase in the pay scale of employees after the integration of disruptive technology.

\section{Impact of technology on Production Activity}

12. With the help of new technology, the company now produces more quality products.

13. New disruptive technology has helped in increasing the overall production output.

14. There is an improvement in the manufacturing process due to the disruptive technology.

15. Due to disruptive technology, the overall production cost is reduced.

16. With the help of using disruptive technology, the cost of delays in production is overcome.

17. By using disruptive technology, production waste has been managed properly.

\section{Impact of technology on Organisation Performance}

18. Disruptive technology has helped in improving the overall organisation performance.

19. By using disruptive technology, high organisation profit is achieved.

20. Using disruptive technology makes the organisation growth reliable and consistent. 